\title{
Media Violence and Judgments of Offensiveness: A Quantitative and Qualitative Analysis
}

\author{
Sarah M. Coyne \\ Brigham Young University - Provo, smcoyne@byu.edu \\ Mark A. Callister \\ Brigham Young University - Provo \\ Douglas A. Gentile \\ lowa State University \\ Emily Howard \\ Brigham Young University - Provo
}

Follow this and additional works at: https://scholarsarchive.byu.edu/facpub

Part of the Other Social and Behavioral Sciences Commons

\section{Original Publication Citation}

Coyne, S. M., Callister, M., Gentile, D. A., \& *Howard, E. (2016). Media violence and judgments of offensiveness: A quantitative and qualitative analysis. Psychology of Popular Media Culture, 5, 372-389.

\section{BYU ScholarsArchive Citation}

Coyne, Sarah M.; Callister, Mark A.; Gentile, Douglas A.; and Howard, Emily, "Media Violence and Judgments of Offensiveness: A Quantitative and Qualitative Analysis" (2015). Faculty Publications. 4022. https://scholarsarchive.byu.edu/facpub/4022 accepted for inclusion in Faculty Publications by an authorized administrator of BYU ScholarsArchive. For more information, please contact ellen_amatangelo@byu.edu. 


\title{
Media Violence and Judgments of Offensiveness: A Quantitative and Qualitative Analysis
}

\author{
Sarah M. Coyne and Mark A. Callister \\ Brigham Young University
}

\author{
Douglas A. Gentile \\ Iowa State University
}

\author{
Emily Howard \\ Brigham Young University
}

\begin{abstract}
Although many studies examine the behavioral effects of viewing media violence, there is little research on whether such violence is perceived as offensive to viewers. Accordingly, the current study examines whether media violence is offensive to viewers and whether feelings of offense mediate the relationship between viewing media violence and aggressive behavior. Participants consisted of 1,429 emerging adults from 2 different Universities in the United States. Results revealed that compared with other content in the media, media violence is perceived as relatively inoffensive. Certain situational (context, genre, and type of violence) and viewer characteristics (gender and religiosity) influenced feelings of offensiveness for media violence. Feelings of offensiveness mediated the association between media violence and aggression, but for women only. Finally, qualitative analyses revealed a host of reasons why viewers are offended or not by media violence. Results are discussed in the context of the General Aggression Model.
\end{abstract}

Keywords: media violence, offensiveness, physical aggression, relational aggression, gender

In the video game Manhunt, players are murder, maim, and torture victims as they advance through levels of the game, gaining rewards for making the killings bloodier, more horrific, and more gruesome. Manhunt represents one of many games within the genre of extreme violence found in today's gaming world. Such violence is not limited to video and computer games, but finds expression in film, TV, music, books, and advertising, raising concerns that such ubiquity and intensity desensitizes and promotes aggression (Anderson et al., 2003). The potential impact on young audiences con-

This article was published Online First March 23, 2015. Sarah M. Coyne and Mark A. Callister, School of Family Life, Brigham Young University; Douglas A. Gentile, Department of Psychology, Iowa State University; Emily Howard, School of Family Life, Brigham Young University.

Correspondence concerning this article should be addressed to Sarah M. Coyne, Brigham Young University, School of Family Life, JFSB 2087, Provo, UT 84602. E-mail: smcoyne@byu.edu tinues to alarm parents, policymakers, media critics, and researchers alike.

Although a causal relation between media violence and aggression has been established in media studies (Anderson et al., 2003, Bushman \& Anderson, 2001), this offers only part of the picture. Certainly, establishing connections between violent content and various outcomes is critical in our understanding of the development and expression of aggression. Nonetheless, probing more deeply into factors that influence consumer perceptions of violence is equally valuable. Not all portrayals of violence have the same effects, and individuals also differ in how they understand and learn from media portrayals.

Huesmann et al. (1983) demonstrated that children's aggressive behaviors could be reduced by teaching children that violence is not as acceptable in the real world as shown on TV and that imitating such violent portrayals is inappropriate. Thus, changing or altering how children interpreted violent content led to attitudinal and behavioral changes, providing insight into the potential mediating role of appropriateness judgments on violence and aggression. 
A related concept worthy of inquiry deals with feelings of offensiveness. Although many studies apply predetermined criteria for what constitutes violent content, the reality that what is grossly offensive to one may be good entertainment to another is often left a peripheral consideration (or accepted as statistical "noise" in the experiment). It is likely, however, that such judgments could mediate how consumers respond to violent content. For instance, consumers with limited exposure to violent media may find such portrayals patently offensive, rejecting or denouncing such behaviors, whereas those desensitized through heavy exposure may prove less offended. Gender, religiosity, and other demographic characteristics may similarly contribute to perceptions of offensiveness. These types of demographic characteristics have been found to moderate how concerned parents are about different types of content for their children (Gentile, Maier, Hasson, \& de Bonetti, 2011). The medium displaying the violence may lessen or heighten feelings of offensiveness simply by virtue of the fact that it was read, listened to, or watched. The social context, such as the presence of children in the room, may also influence perceptions. These types of factors have the potential to regulate how consumption of violent media content translates into emotional, cognitive, and behavioral outcomes.

Research into offensiveness of media violence has, to some extent, taken backseat to sexual content in the media (ASA, 2002). The Advertising Standards Authority, for instance, ranks sexual portrayals of children, degrading sexual portrayals of women, words and images that are unsuitable for children, and demeaning (nonsexual) portrayals of women, higher in offensiveness than violent portrayals. As expected, sexuality and indecent language are hallmarks of offensive content, with content that degrades human dignity or exploits children being seen as particularly offensive (Shimp \& Stuart, 2004). This current study acknowledges the importance and seriousness of this type of research, while attempting to add to the body of knowledge on the offensiveness of violent media content.

Thus, despite the prevalence of both graphic violence in the media and research documenting the harmful effect of such content (Anderson et al., 2003), only a modicum of research examines whether media violence is actually offensive to viewers, what factors influence such judgments, and whether feeling offended (or not) mediates any associations with aggressive behavior.

Accordingly, the purpose of the current study is threefold: (a) to examine how media violence, sexual content, and profanity differ in terms of offensiveness evaluations; (b) to explore how contextual and personal variables (e.g., medium, social context, gender, religiosity) relate to perceptions of offensiveness in media violence; and (c) to examine whether feelings of offense mediate relationships between exposure to media violence and aggressive behavior.

\section{Media Violence as Offensive Content}

Research on feelings of offensiveness of media content is rare, and there is no clear accepted definition. Several definitions describe offensive content as material that violates community norms regarding objectionable content (Timmer, 2009) or refers to something that is unpleasant or objectionable to the viewer, in a physical, emotional, or a moral sense (Christy \& Haley, 2008). Other authors describe feelings of offensiveness as an experience of disgust that is associated with feeling uncomfortable in a person's surrounding (Olivera La Rosa \& Roselló Mir, 2013). However, viewers may judge some media content as merely annoying or unpleasant-not reaching the level of disgusting-yet still label such material as offensive. What is ultimately deemed offensive to viewers, therefore, may arise from emotional responses that range from milder annoyance, discomfort, or unpleasantness to the stronger emotion of disgust, reflecting a large range of potential responses.

Although shameful and embarrassing appear to be companion terms with offensive, a close examination of the terms reveals a distinction in terms of the directed focus. Arguably, content deemed shameful and embarrassing implies a critical evaluation or condemnation of the source of the objectionable material. Offensive, on the other hand, points more to receiver appraisals or judgments of the material as to its alignment with personal values or codes of appropriateness. This study focuses more on offensiveness arising out of judgments of the media content. 
Judgments of offensiveness appear to lead to a common behavioral response that runs through the range of evoked emotions, which is a feeling of repulsion or desire to distance oneself from the content, either due to its discomforting organic or psychological characteristics. In the current study, therefore, we use the term offensive to involve feelings of disgust and/or discomfort (Olivera La Rosa \& Roselló Mir, 2013; Shimp \& Stuart, 2004) that possess a repulsive or repelling force in reaction to profanity, violent, or sexual material.

The potential role of offensiveness in response to violent material is better understood within the tenets of the general aggression model (GAM; Anderson \& Bushman, 2002). The GAM emphasizes the "person in the situation" (Anderson \& Bushman, 2002), highlighting the importance of studying both the personal characteristics and the situational variables contained in a consumption "episode." At the heart of the model is the use of knowledge structures (i.e., learned concepts). These structures develop from experience, become automatized with time, connect to affect and beliefs, influence behaviors, guide interpretations, and lead to behavioral responses to our physical and social environment (Anderson \& Bushman, 2002).

In examining more closely the "person" in the situation, the GAM explains that person variables may include all internal factors that an individual brings to the consumption situation, such as genetics, personal traits, current states, scripts, attitudes, beliefs, aggressive orientations, and so forth (Carnagey \& Anderson, 2003). In addition, situational variables exist within the consumption setting, potentially affecting responses to media content, such as the social context, aggressive cues, rewards, punishments, and so forth. These input variables combine to affect how individuals appraise and interpret content, and influence the internal state and ultimate responses of individuals to the content.

Three routes, according to GAM, affect internal states: physiological arousal, emotional affect, and thoughts and accessibility of learned concepts. These routes, in turn, influence how media content is appraised or judged, leading ultimately to decision processes that may involve thoughtful or impulsive action. For example, several research studies show that heavy viewers of media violence have reduced physiological or neurological arousal to viewing media violence (Bartholow, Bushman, \& Sestir, 2006; Carnagey, Anderson, \& Bushman, 2007; Engelhardt, Bartholow, Kerr, \& Bushman, 2011; Funk, 2005; Krahé et al., 2011; Thomas, Horton, Lippincott, \& Drabman, 1977). Blunted physiological or neurological responses tend to be associated with increased aggressive behavior after viewing (Bartholow et al., 2006; Engelhardt et al., 2011). As for emotional affect, viewers of media violence experience a reduction in feelings of sympathy or empathy for victims of violence, leading to greater likelihood of subsequent aggressive behavior (Bushman, Chandler, \& Huesmann, 2010; Fanti, Vanman, Henrich, \& Avraamides, 2009; Funk, Baldacci, Pasold, \& Baumgardner, 2004; Krafka, Linz, Donnerstein, \& Penrod, 1997; Linz, Donnerstein, \& Penrod, 1998; Wilson, 1989). Finally, media violence as a situational variable can influence internal states through cognitive script activation. As individuals consume media violence with greater regularity, aggressive constructs become more accessible, and the threshold for activating aggressive scripts is reduced. Research indicates that continued exposure to violent content renders previously objectionable actions and events logically more acceptable with time. For example, men are more accepting of rape myths (i.e., blaming a woman for being raped) after having viewed violent pornography (Linz \& Donnerstein, 1989).

Anderson and Bushman (2002) note that studying personal and situational factors within a GAM framework "leads to a simpler and more comprehensive understanding of human aggression than is possible using the minitheory approach . . . [and] indicates the types of underlying processes to examine to see how various inputs lead to aggressive (or nonaggressive) behavior" (p. 35). In the sections below, we examine some understudied personal and situational inputs that potentially mediate internal states and the appraisal of media violence and broaden our understanding of consumer responses to such portrayals. 


\section{Personal Inputs of Viewers}

As noted, there is a paucity of research examining the role of personal inputs in determining the level of perceived offensiveness to media violence that may influence arousal, cognition, and affect. A few studies suggest that women tend to be more offended by certain media content than men (ASA, 2002), and this effect is particularly strong for women over the age of 50 (Fahy, Smart, Pride, \& Ferrell, 1995). Women tend to assign higher offensiveness ratings to all examples of indecent language (Sapolsky, Shafer, \& Kaye, 2010), as well as nudity, sexist, or racist themes (Waller, 1999). From the content provider side, some studies suggest that sexual content receives much stricter ratings than does violent content (Gentile, 2008; Leone, 2002). Other research has enhanced our understanding of gender differences in aggressive tendencies and types of aggression enacted (i.e., direct vs. indirect), but issues focusing on feelings of offensiveness toward violence are largely unknown. The research into gender and offensiveness indicates that women may prove more sensitized and men more desensitized toward media violence, in turn influencing cognition, affect, and arousal.

Several studies also suggest that religiosity may influence feelings of offense. Sapolsky et al. (2010) found that those who regularly attended church were more offended by indecent language than those who did not attend church or attended church less regularly. Additionally, religious individuals were also more offended viewing advertisements of certain products (Christy \& Haley, 2008). Although there are only a few studies regarding religion and offensiveness, these studies indicate that religiosity may influence feelings of offense. In a national study, more religious families were more interested in controlling children's access to violent, sexual, and other media content (Gentile et al., 2011). Arguably, religious instruction often emphasizes peaceful resolution to interpersonal conflict, the "turning of the other cheek," and showing love, compassion, and charity toward others. The inculcation of such values, over years of religious instruction, may influence the framing and responses to violent media content. The exact role of religiosity as an input variable in the GAM and its influence on feelings of offensiveness is unknown, but it may offer insight into how consumers respond to violence.

\section{Situation Inputs}

In addition to personal factors, several understudied situational variables operating during the consumption episode may be important. For instance, the purpose to which the content is used may affect actual perceptions. In a recent study-although not specifically related to media violence-approximately three-quarters of respondents indicated that using shocking content in order to make an important point was appropriate for government, charities, and other nonprofit organizations. However, when such content is used within the context of advertisements, for the same purposes, only $34 \%$ thought it appropriate (ASA, 2002). This finding points to the possibility that media type may influence perceptions of offensiveness.

Unfortunately, research in this area is limited to the realm of advertising instead of the more traditional forms of media (film, TV programming, video games, books, and music). Nonetheless, a few comparisons indicate that more invasive media types are more likely to promote offense (ASA, 2002; Christy \& Haley, 2008). For instance, the Advertising Standards Authority divides media into two types: invasive or "push" media that is outside of the viewer's control, such as billboards, direct mail, or newspapers; and "pull" media, which viewers find less invasive and more easily controlled, such as magazines and the Internet (ASA, 2002). As expected, the more invasive and less controlled the content, the more offensive. Similarly, Christy and Haley (2008) found that Internet pop-up advertisements and billboards were consistently rated as the most offensive. Therefore, the appearance of violent content in push media, where consumers have limited control of exposure, may lead to greater feelings of offensiveness.

Regardless of media type, adults view adult themes as more offensive when delivered through a medium easily available to young, impressionable audiences (ASA, 2002). Similarly, adults may deem material as offensive when children are present in a consumption setting, whereas the same content may engender little to no reaction when children are absent. 
Thus, the social context may exercise some influence on perceptions of offensiveness.

Characteristics of each medium may also influence perceptions of offensiveness. For instance, books stimulate the imagination, allowing readers to construct the violent images as described in writing and temper or enhance the violence, offering some degree of control in how the violence is portrayed. Violent images provided in graphic detail in a visual format (and perhaps accompanied with arousing music), such as film and TV (Riddle, Eyal, Mahood, \& Potter, 2006), confront more of the senses and viewers are under the control of the content creators.

Additionally, the level of realism in the depictions of potentially offensive content may influence how that content is perceived. Fantasy, animated, and comedic depictions of violence are generally seen as less offensive. Indeed, such displays of violence are generally viewed as acceptable for children's TV programs and films (Pottler et al., 1995; Potter \& Smith, 2000; Wilson et al., 2002), despite the fact that these types of displays can have the same behavioral level effects as more realistic or graphic displays (Anderson, Gentile, \& Buckley, 2007).

\section{Aim of the Current Study}

In sum, though there has been some research on whether viewers are desensitized to viewing media violence, there has been almost no research to our knowledge on whether they feel offended after viewing such content. Theoretically, the two are linked, but almost all desensitization research has focused on obtaining physiological or neurological measures as evidence for desensitization (Engelhardt et al., 2011), or asking whether they feel empathy toward victims (Funk et al., 2004). Feeling offended by media violence affects physiological, emotional, and cognitive reactions. Although other media content has been examined from an "offensive" viewpoint, to our knowledge this is the first study to examine media violence from such a perspective in any detail.

The first aim of the study is to examine the extent to which viewers are offended by violence in the media, specifically examining how person factors relate to feelings of offense, such as gender, religiosity, and amount of violent media consumption. Based on previous research, we predict that women will be more offended by media violence (as a whole) compared with men (ASA, 2002), that religiosity would be positively correlated with feelings of offensiveness (Sapolsky et al., 2010), and that greater preference and reported viewing of media violence will be correlated with less offense.

In examining situation factors, based on previous research, we hypothesize that offensiveness ratings will be greater for more graphic and realistic depictions of violence. We also anticipate that viewers will be more offended if violence is used in advertising, specifically as a way to sell products (Christy \& Haley, 2008). We predict that violence in less visual media (such as books or music) where the violence would tend to be less graphic and more under the control of the individual's imagination may render lower ratings of offensiveness. We also predict that the social context will influence perceptions of offensiveness, with viewers being most offended when viewing violence with children (Shimp \& Stewart, 2004).

We also examine how feelings of offensiveness toward media violence compare with other media content, including sex and profanity. Given the ratings by the ASA (2002), we predict that sexual content will receive the highest ratings of offensiveness, followed by profanity, and then violence.

Finally, this study explores participant reasons for their reactions to media violence. We use qualitative techniques to examine responses, treating such techniques as more exploratory in nature. To our knowledge, this study represents one of the first qualitative studies on perceptions of violence in the media. Finally, this study examines the potential mediating role of offensiveness in the relationship between media violence exposure and aggressive behavior. Specifically, we predict that feelings of offensiveness will mediate consumer reactions to media violence.

\section{Method}

\section{Participants}

Participants consisted of 1,429 individuals $(60 \%$ female, $\mathrm{M}$ age $=20.49, S D=2.992)$. Approximately half of the sample was recruited from undergraduate classes at a state university 
in the Midwest and about half the sample was from a private religious university in the Western United States of America. For stated religion, 46\% reported being Latter-Day Saints (LDS; Mormons), 14\% Catholic, 13\% Christian (nondenominational), 7\% atheist, and the other $20 \%$ reported being a variety of religions (Methodist, Protestant, Baptist, Buddhist, Jewish, Lutheran, and Hindu).

\section{Measures and Procedures}

Participants completed a series of online questionnaires described below.

Media offensiveness. Participants were first provided with a definition of "offended" which was feelings of repulsion and/or feeling uncomfortablelawkward. There appears to be little consensus on how to measure feelings of "offensiveness" in the field, but this definition captures two aspects of offensiveness: feelings of both disgust and feeling uncomfortable (Shimp \& Stuart, 2004). They were then asked a series of questions regarding how offended they were when exposed to various behaviors in the media. All responses were measured on a 7-point Likert scale $(1=$ not offended to $7=$ highly offended). A portion of the questionnaire is included in Appendix.

Genre. Participants were given a definition of violence (See Appendix: Coyne, Nelson, \& Underwood, 2010) and were then asked how offended they would be when encountering physical violence in six different mediums (movies, books, $\mathrm{TV}$, advertising, music, and video games), as well as in real life (e.g., you witness a fight or a mugging on the street). Items were analyzed individually. Nonetheless, reliability tests were conducted on overall levels of ratings of offensiveness for the six genres and showed good reliability $(\alpha=.92)$.

Context. Four questions measured how offended participants would be if viewing media violence with a variety of individuals (parents, member of the opposite sex, peers, children). Again, reliability scores were computed for all context items and showed good reliability $(\alpha=$ .91 ), though individual items were used in all analyses.

Profanity and sexual content. Participants were also given definitions of sexual content (Ward, 2003) and profanity (Coyne, Stockdale, Nelson, \& Fraser, 2011) and were asked how offended they are when exposed to sexual content and profanity in the media using the same scale as used for media violence. Items were analyzed individually in subsequent analyses.

Rationale. Participants were asked one final open-ended question: "Why (or why not) are you offended by violence in the media?"

Religiosity. Religiosity was measured using four items from the Santa Clara Strength of Religious Faith Questionnaire (Lewis, Shevlin, McGucklin, \& Navrátil, 2001). Questions were based on a 4-point Likert scale ranging from 1 (strongly disagree) to 4 (strongly agree). Sample questions include, "I pray daily" and "my faith impacts many of my decisions." Higher scores indicate greater perceived religious influence on identity, meaning, life decisions, and religious behaviors. Reliability was highly acceptable $(\alpha=.96)$.

Aggression. Participants were asked to read a series of statements and indicate how well each described him or her on a 5-point Likert scale $(1=$ very inaccurate to $5=$ very accurate; Leavitt, Nelson, Coyne, \& Hart, 2013; Nelson, 2005; Nelson, Coyne, Swanson, Hart, \& Olsen, 2014; Stockdale, Coyne, Nelson, $\&$ Padilla-Walker, 2013). The physical aggression subscale consisted of two questions that measured physical forms of aggression against others (e.g., "Threaten to hit [or hit] other people"). Relational aggression consisted of three items measuring indirect forms of aggression (e.g., "Spread rumors about others"). Reliability for both scales was acceptable (physical aggression, $\alpha=.72$; relational aggression, $\alpha=.70$ ).

Media violence exposure. Participants were asked to list their three favorite TV programs. For each they indicated on a 7-point scale $(1=$ less than once a month to $7=6$ or more times per week) how frequently they viewed each program. Participants were also provided with a definition of physical violence and were asked to rate each program for violent content $(1=$ none to $7=$ very high amount $)$. The violent content for each program was multiplied by the frequency viewed to give each participant a media violence exposure score (with higher scores indicating high levels of violent content that are viewed frequently). Such a method is commonly used in media violence studies (Anderson et al., 2007; Gentile, Lynch, Linder, \& Walsh, 2004) and has been shown to correlate highly with expert ratings of media violence (Gentile et al., 2010). 


\section{Results}

\section{Descriptive Statistics}

A series of mixed ANOVAs were conducted to assess gender differences and general differences across medium, contexts, and content. For medium, the ANOVA revealed significant main effects for medium, $F(6,1355)=508.41, p<$ .001 , partial $\eta^{2}=.69$, gender, $F(1,1360)=$ 243.43, $p<.001$, partial $\eta^{2}=.15$, and an interaction between medium and gender, $F(6$, $1355)=15.92, p<.001$, partial $\eta^{2}=.07$. See Table 1 for means and standard deviations. Post hoc analyses revealed that participants were most offended by real life violence compared with any media violence (all post hoc comparisons $p<.001$ ). However, there were also differences by medium. Overall, participants were most offended by violence in advertising and music as compared with other types (all comparisons are $p<.001$ ). Then, in order of offensiveness, video games, TV, movies, and finally books (all comparisons are $p<.001$ ). For gen-

Table 1

Media Violence Offensiveness for Medium, Context, and Content

\begin{tabular}{|c|c|c|c|c|c|c|}
\hline & \multicolumn{2}{|c|}{ Men } & \multicolumn{2}{|c|}{ Women } & \multicolumn{2}{|c|}{ Overall } \\
\hline & Mean & $S D$ & Mean & $S D$ & Mean & $S D$ \\
\hline \multicolumn{7}{|l|}{ Medium $^{a}$} \\
\hline Real world & 4.84 & 1.95 & 5.99 & 1.46 & 5.53 & 1.77 \\
\hline Advertising & 2.78 & 1.70 & 4.23 & 1.78 & 3.65 & 1.88 \\
\hline Music & 3.04 & 1.86 & 4.04 & 1.78 & 3.64 & 1.88 \\
\hline Video games & 2.46 & 1.80 & 3.97 & 2.00 & 3.37 & 2.06 \\
\hline Television & 2.52 & 1.61 & 3.73 & 1.76 & 3.25 & 1.80 \\
\hline Movies & 2.44 & 1.63 & 3.58 & 1.76 & 3.12 & 1.79 \\
\hline Books & 2.06 & 1.32 & 3.01 & 1.58 & 2.63 & 1.55 \\
\hline \multicolumn{7}{|l|}{ Context ${ }^{\mathrm{b}}$} \\
\hline Children & 4.73 & 1.89 & 5.95 & 1.43 & 5.47 & 1.74 \\
\hline Parents & 3.66 & 2.05 & 3.75 & 1.82 & 4.32 & 1.99 \\
\hline Opposite sex & 3.79 & 2.04 & 4.50 & 1.87 & 4.22 & 1.97 \\
\hline Peers & 3.05 & 1.88 & 4.24 & 1.83 & 3.77 & 1.94 \\
\hline \multicolumn{7}{|l|}{ Content (in TV) ${ }^{\mathrm{c}}$} \\
\hline Violence & 2.51 & 1.61 & 3.74 & 1.76 & 3.25 & 1.81 \\
\hline Sexual content & 3.93 & 2.34 & 4.51 & 2.10 & 4.28 & 2.22 \\
\hline Profanity & 3.53 & 2.26 & 4.18 & 2.11 & 3.92 & 2.19 \\
\hline
\end{tabular}

Note. Gender differences are significant for every comparison at $p<.001$.

${ }^{a}$ All comparisons for medium are significant $(p<.001)$ for every comparison except between advertising and music. ${ }^{\mathrm{b}}$ All comparisons for context are significant for every comparison $(p<.001)$. ${ }^{\mathrm{c}}$ All comparisons for content are significant for every comparison $(p<.001)$. der, women were significantly more offended by media violence in every genre and in real life (all comparisons are $p<.001$ ). Regarding the interaction, the pattern of results for men and women were very similar except for music. Men were most offended by media violence in music, while women were most offended by advertising. Men, compared with women, were also substantially less offended by media violence in video games in comparison with other types.

For context, the ANOVA revealed significant main effects for context, $F(3,4173)=$ 702.44, $p<.001$, partial $\eta^{2}=.34$, gender, $F(1,1391)=140.59, p<.001$, partial $\eta^{2}=$ .09 , and an interaction between context and gender, $F(3,4173)=19.09, p<.001$, partial $\eta^{2}=.01$. See Table 1 for means and standard deviations. For context, participants were most offended when viewing media violence with children, then with their parents, with a member of the opposite sex, and finally, with their peers (all comparisons against each other are $p<.001$ ). Again, women were more offended by media violence in all different contexts than men (all comparisons are $p<$ .001). An inspection of the interactions revealed a similar pattern for gender, except that men were substantially more offended when viewing media violence with a member of the opposite sex, as compared with the pattern set by women.

Finally, we compared feelings of offensiveness of media violence as compared with sexual content and profanity in the media. These are compared in the context of $\mathrm{TV}$, because this medium is used most frequently by this age group. When compared with other potentially offensive content in the media, a mixed ANOVA revealed a significant main effect for type of content, $F(2,2748)=208.16, p<$ .001 , partial $\eta^{2}=.17$, gender, $F(1,1374)=$ 70.38, $p<.001$, partial $\eta^{2}=.05$, and an interaction between content and gender, $F(2$, $2748)=27.97, p<.001$, partial $\eta^{2}=.02$. See Table 1 for means and standard deviations. Compared with men, women were more offended by violence, sexual content, and profanity in the media (all comparisons $p<$ $.001)$. On the whole, participants were most offended by sexual content, then profanity, and least offended by violence in the media (all comparisons $p<.001$ ). For the interac- 
tion, this pattern was similar for men and women; however, men were substantially less offended by media violence than women, in comparison with other content.

\section{Correlations and Gender Differences for Main Variables}

Bivariate correlations were computed for media violence exposure, physical aggression, relational aggression, media violence offensiveness, and religiosity. All media variables in this analysis are in the context of TV; we collected media violence ratings for each participant's favorite TV programs, and participants spend more time viewing media content in TV programs than other media (Kaiser Family Foundation, 2010). See Table 2 for correlation matrix. The pattern of results was similar for men and women. For both, media violence offensiveness was negatively correlated with viewing media violence, physical aggression, relational aggression, and positively correlated with religiosity. Media violence exposure was positively correlated with both physical and relational aggression and negatively correlated with religiosity. Religiosity was also negatively correlated with physical and relational aggression. Finally, both subtypes of aggression were positively correlated. All comparisons were significant at the $p<.001$ level.

A MANOVA on these variables revealed a significant overall effect for gender, $F(5$, $1274)=37.41, p<.001$, partial $\eta^{2}=.13$. See Table 2 for means and standard deviations. Men were exposed to significantly more media violence, $F(1,1278)=26.16, p<.001$, partial $\eta^{2}=.02$, and were also more physically aggressive, $F(1,1278)=10.94, p<.001$, partial $\eta^{2}=.01$, than women. Conversely, women were more offended by violence on TV, $F(1$, $1278)=174.04, p<.001$, partial $\eta^{2}=.12$, and were more religious than men, $F(1,1278)=$ $12.90, p<.001$, partial $\eta^{2}=.01$. There was no gender difference for relational aggression, $F(1$, 1278) $=.002, p=.96$, partial $\eta^{2}=.00$.

\section{Structural Equation Model}

Using structural equation modeling with AMOS software, a model was estimated examining whether feelings of offense mediated the relationship between media violence exposure and different subtypes of aggression (see Figure 1). Latent variables were constructed where possible. Religiosity was used as a control variable in the model. To examine gender differences, multiple group analyses were conducted comparing a fully constrained model with a fully unconstrained model, which resulted in a decrease in model fit. Analyses suggested that model fit was best when intercepts, factor loadings, residual variances, and structural paths were allowed to vary across groups. This final fully unconstrained model had acceptable fit $\left(\chi^{2}(162)=446.66, p<.001\right.$, Comparative Fit Index $=.97$, Tucker-Lewis Index $=.96$, Root Mean Square Error of Approximation $=.04$ ). Given that the model was exploratory, paths where results failed to reach the critical value of significance, but were "trending" toward significance $(p<.10)$, were described as "marginally significant" in the interpretation. According to Vogt (2000), margin-

Table 2

Correlations and Gender Differences Between Main Variables

\begin{tabular}{lccccc}
\hline & 1 & 2 & 3 & 4 & 5 \\
\hline$M$ & 2.44 & 11.57 & 1.59 & 2.24 & 3.41 \\
$S D$ & 1.56 & 9.66 & .83 & .72 & 1.55 \\
1. Media violence offensiveness & - & $-.22^{* *}$ & $-.12^{* *}$ & $-.17^{* *}$ & $.28^{* * *}$ \\
2. Media violence exposure* & $-.28^{* *}$ & - & $.33^{* *}$ & $.18^{* *}$ & $-.38^{* *}$ \\
3. Physical aggression* & $-.17^{* *}$ & $.22^{* *}$ & - & $.38^{* *}$ & $-.29^{* *}$ \\
4. Relational aggression & $-.22^{* *}$ & $.18^{* *}$ & $.34^{* *}$ & - & $-.22^{* *}$ \\
5. Religiosity* & $.35^{* *}$ & $-.34^{* *}$ & $-.18^{* *}$ & $-.24^{* *}$ & - \\
$M$ & 3.73 & 9.66 & 1.44 & 2.25 & 3.71 \\
$S D$ & 1.77 & 5.95 & .77 & .69 & 1.40 \\
\hline
\end{tabular}

Note. $\quad M=$ Mean. $S D=$ Standard Deviations. Upper diagonal: descriptive statistics and correlations for men; lower diagonal: descriptive statistics and correlations for women.

* Significant mean gender difference at $p<.001 .{ }^{* *} p<.001$. 


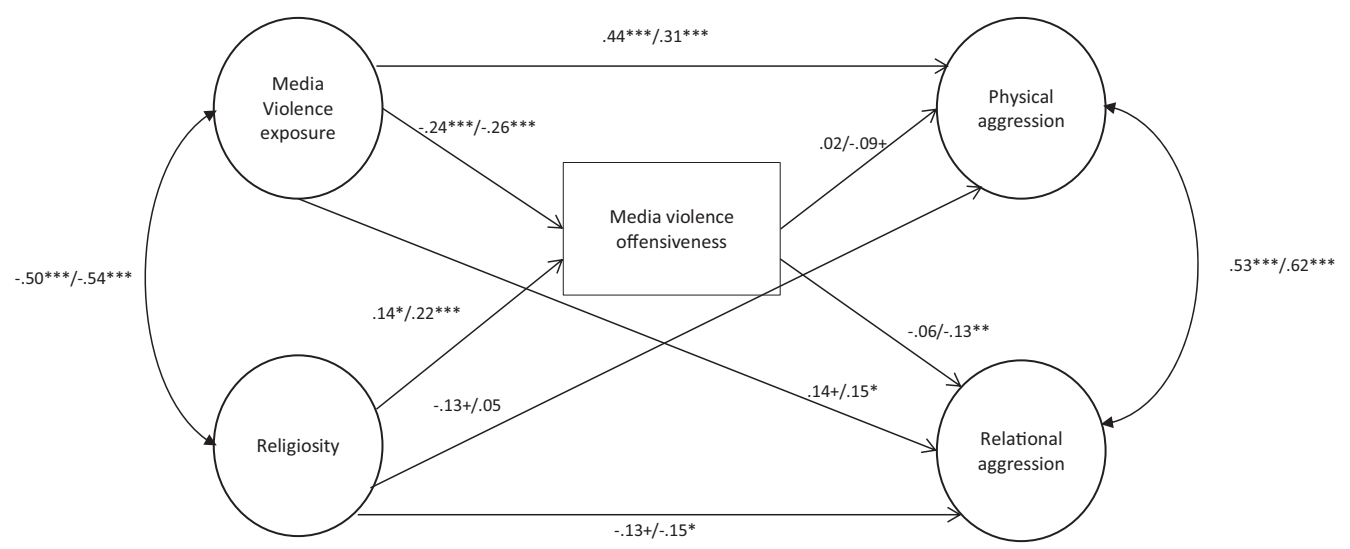

Figure 1. Associations between media violence exposure and aggression with media violence offensiveness as a mediator. All values represent standardized beta weights. The figure before the slash represents associations for men, after the slash for women: $\chi^{2}(162)=446.66$, $p<.001$, Comparative Fit Index $=.97$, Tucker-Lewis Index $=.96$, Root Mean Square Error of Approximation $=.04{ }^{\dagger} p<.10{ }^{*} p<.05 .{ }^{* *} p<.01{ }^{* * * *} p<.001$.

ally significant results in exploratory models may be relevant, and should merit some discussion.

Results suggested that for men, media violence exposure was positively associated with physical $(\beta=.44, p<.001)$ and relational aggression $(\beta=.14, p=.05)$ and was negatively associated with offensiveness $(\beta=-.24$, $p<.001)$. However, men's judgments of media violence offensiveness were not related to either physical or relational aggression. For women, media violence exposure was also positively associated with physical $(\beta=.31, p<.001)$ and relational aggression $(\beta=.15, p<.05)$. Women's judgments of media violence offensiveness were negatively associated with relational aggression $(\beta=-.13, p<.01)$, and with physical aggression $(\beta=-.09, p=.05)$. Bootstrapping analyses for indirect effects based on 2,000 bootstrapping resamples and a 95\% CI revealed that offensiveness significantly mediated the relationship between media violence and relational aggression $(p<.01)$ and was marginally significant for physical aggression $(p=.07)$.

Religiosity was positively associated with media violence offensiveness for both men $(\beta=.14, p<.05)$ and women $(\beta=.22, p<$ $.001)$. It was also significantly negatively associated with media violence exposure for both men $(\beta=-.50, p<.001)$ and women $(\beta=-.54, p<.001)$. Finally, religiosity was negatively associated with relational aggression for women $(\beta=-.15, p<.05)$ and was marginally negatively associated with physical $(\beta=-.13, p=.06)$ and relational aggression $(\beta=-.13, p=.06)$ for men (at the level of a trend).

\section{Qualitative Data Analyses}

We used grounded theory to analyze the open-ended question (Lofland, Snow, Anderson, \& Lofland, 2006; Strauss \& Corbin, 1998). In particular, according to this approach coding should be "pursued in a persistent and methodical fashion" (Lofland et al., 2006, p. 196) where the researchers derive conceptual constructs and models from the data as opposed to the coders' preexisting conceptions. The coding consisted of three major stages. In stage 1, 20\% of the data were coded by two coders using "initial coding," which involved coding the answers for general themes (Lofland et al., 2006). In stage 2, all answers were coded by two coders using "focused coding," which involved breaking down the comments into conceptually distinct categories. Categories were grounded in the data and developed through the coding process. Several categories were modified or omitted during this stage. At the end of this stage, categories that were seen as similar were collapsed together. Categories were not mutually exclusive and some responses could be coded in 
more than one category. As a result of this stage of analysis, we identified seven prominent reasons for being offended (or not) by media violence. In stage 3, quotations that typified themes were identified. Across the coding process, the two coders met together frequently to discuss the development of themes and any issues that arose. Any disagreements with coding were discussed until both coders could agree upon a response (100\% of answers were agreed upon).

Across the sample, there were 1,360 valid responses to this item ( $92 \%$ of the sample). Reponses were first coded as to whether participants felt they were offended by media violence or not. Based upon our coding, $32 \%$ of the sample were offended by media violence, $35 \%$ were not offended, and $18 \%$ were sometimes offended. Approximately $93 \%$ of responses were captured by seven different themes (7\% of responses were not classifiable into one of the themes). Below, we delineate the different reasons why individuals reported being offended or not by media violence.

Reasons for being offended. There were four main reasons why participants reported being offended by media violence. The first reason participants reported for being offended was that the violence was inhumane (representing $18 \%$ of all responses). This category identified violence in the media as being inherently wrong or immoral because it was portraying harm toward another person. For example, a 20-year-old LDS female responded, "It is disrespectful and hurtful to watch. There is rarely any reason to use violence against another human being." Another example from a 20-yearold Atheist male reported, "I'm offended by violence because it is two or more people purposely injuring each other. The notion of 'might makes right' deeply revolts and angers me, so people using variations of it in media upsets me. Thuggish and violent people being portrayed as heroes because of their strength offends me, because it is a terrible moral lesson."

Participants also reported that they were offended by media violence because they empathized with victims. This reflected $10 \%$ of the overall responses and participants mostly said they did not like to see other people being hurt. One participant reported, "It is almost physically painful for me to see someone else in pain" (19-year-old Catholic female), while another said "I imagine myself being in the posi- tion of the victim. If I don't like violence used on me, then I do not like to be expose[d] to it" (20-year-old Pentecostal female).

Other participants reported that they were only offended by certain types of media violence (we collapsed two categories for this code). For example, $7 \%$ reported being offended by graphic forms of media violence, for example, portrayals that were unnecessarily bloody or extensive. For example, one participant reported, "I get offended by excessive violence (dismemberment, torture, domestic violence), but not normally by run of the mill violence from everyday media" (22-year-old nondenominational male). Another reported, "Depends on how it's used. Horror movies that use bloody, gory, disgusting, VERY brutal violent torture scenes for the sole purpose to entertain or to horrify is not what I want to see" (24-year-old LDS male). Other participants reported that they were not typically offended by media violence, but it was conditional on the context, for example if it was portrayed against children, women, in a racist context, against homosexuals, or other. This view represented $10 \%$ of overall responses. One participant reported, "It depends on the situation the violence is occurring. For example, killing the bad guy versus a husband killing his wife or beating her." (20-year-old nonreligious female). Another reported, "Depends of the context. I absolutely cannot tolerate sexual violence. It literally makes me sick to my stomach when seen in movies or TV. Fighting does not bother me as much." (19-year-old Atheist female).

Finally, 5\% of the sample specifically reported they were offended by media violence because they felt media violence had a direct effect on viewer attitudes or behavior. One participant reported, "because it can affect you in your own life and make you more prone to violence and can dull you toward violence, which in my opinion is equally bad" (31-yearold LDS male). A few specifically reported the research on media violence as a reason for being offended, for example, "I am offended by it, because I have read studies and seen how it can affect young children and the world" (21-yearold LDS female).

Reasons for not being offended. There were three main reasons why participants reported that they were not offended by media violence. Eighteen percent of all responses re- 
ferred to participants being desensitized in some way, that they had viewed so much of it in the media that they no longer had a reaction to its portrayal. One participant reported, "Violence in media is almost normal, so I am not offended, but I know the difference with real life" (32year-old Hindu male). Another reported, "I'm not offended. I imagine you would call it desensitization. Really, I don't care. In fact, I'm fairly violent myself." (19-year-old Atheist male).

Other participants ( $11 \%$ of all responses) reported that they were not offended by media violence because they knew it was unrealistic, though many reported they would be offended by violence in the real world. For example, one participant reported, "I am not generally offended by violence when it is on TV show[s] or a in a movie because I believe it to 'not be real,' but I would get offended if some people were physically assaulting each other outside" (19year-old Christian male). Another reported, "I find that witnessing violence in real life is offensive and actually rather scary. Violence on t.v. or other media is fake and staged. No one really got hurt or it never really happened." (19-year-old Lutheran male).

Finally, $13 \%$ of participants reported that they were not offended by media violence because it is a natural or expected part of human life. Examples included "It's human nature. You can't be offended by people because we are a violent species (20-year-old nonreligious male)," and "I'm not offended by violence, be- cause violence is in everyday life. Whether we like it or not, violence is a part of our world" (19-year-old nondenominational female). Another participant quipped, "Violence is something as old as life. Get used to it." (23-year-old LDS male).

Sample differences. We analyzed the coding across a few different demographic variables. A series of chi-square analyses revealed that men reported being significantly less offended by media violence than women, $\chi^{2}(3)=$ $124.12, p<.001$, and their reasons for being offended (or not) also significantly differed, $\chi^{2}(10)=123.93, p<.001$. An examination of the standardized residuals revealed that men were significantly more likely than women to report being desensitized to violence and that media violence was a natural part of human life. Conversely, women were more likely to report being offended because media violence was inhumane, empathize with victims, and felt viewing such violence had an effect on their behavior (all comparisons $p<.05$ ). No other significant differences in other categories were found.

For religion, we used a median split to dichotomize participants into low $(n=753)$ and high $(n=710)$ religious involvement. Chisquare analyses revealed that highly religious participants were more offended by media violence compared with those with lower religious participation, $\chi^{2}(3)=57.31, p<.001$. Again, reasons for being offended or not being offended differed by religious activity, $\chi^{2}(7)=$

Table 3

Number of Reasons for Being Offended (or Not) by Media Violence by Religious Involvement of Participant

\begin{tabular}{lcc}
\hline & \multicolumn{2}{c}{ Religious involvement } \\
\cline { 2 - 3 } & $\begin{array}{c}\text { Low religious } \\
\text { involvement } \\
(n=753)\end{array}$ & $\begin{array}{c}\text { High religious } \\
\text { involvement } \\
(n=710)\end{array}$ \\
\hline Reasons for being offended by media violence & 97 & 151 \\
Inhumane & 46 & 78 \\
Empathy & 97 & 90 \\
Conditional on a certain type of violence (e.g., graphic) & 31 & 23 \\
Direct effect on viewer & 157 & 138 \\
Reasons for not being offended by media violence & 104 & 44 \\
Desensitized & 76 & 74 \\
Unrealistic & 66 & 33 \\
Expected part of life & & \\
Other diverse responses &
\end{tabular}


56.68, $p<.001$. See Table 3 for frequency of responses. In particular, the answers of highly religious participants reflected that media violence was more inhumane, graphic, and empathized more with victims. Low religious participants reported that media violence was more unrealistic and were also more likely to report a conditional reason for being offended (e.g., violence against children; all comparisons $p<$ $.05)$. Interestingly, there were no differences for the responses describing feelings of desensitization, the idea that violence was natural or expected, or the idea that there was an effect on viewers.

\section{Discussion}

This study highlights the diversity in offensiveness reactions to media violence, ranging from highly offended to no offense. In support of the GAM, both person and situational inputs influence offensiveness responses, which in turn mediate aggressive behaviors.

First, we examined understudied person inputs related to offensiveness. As previously mentioned, person variables include all internal factors individuals bring to the consumption situation, such as personal traits, current states, scripts, attitudes, beliefs, aggressive orientations, and so forth (Carnagey \& Anderson, 2003). In examining gender as a person input, we confirmed our hypothesis that media violence is more offensive to women than men, thus supporting previous research that women are more sensitive to and offended by other types of content (ASA, 2002). Given that women view less violence than men do (both in the media and potentially in the real world), they may be more offended because of their lesser familiarity with media portrayals of violence (Archer, 2004). Indeed, when examining the reasons why men and women report not being offended by media violence, men are significantly more likely than women to report being desensitized by media violence and that violence is an expected part of life.

In addition, consumers' history with violent content relates to feelings of offensiveness. Specifically, lower exposure predicts greater offense when exposed to media violence and aggression (physical and relational). In the structural equation model, media violence offensiveness partially mediates the effect of media violence exposure on aggressive behavior, but for women only. In other words, for both sexes, higher media violence exposure predicts greater aggressive behavior. In addition to this general effect, if women are offended by media violence when they see it, this reduces the risk of aggressive behavior. This was significant for relationally aggressive, but only marginally significant for physical aggression. For men, however, being offended by media violence did not partially mediate the general effect for either type of aggression.

There may be a few explanations for this finding. First, media violence is less offensive to men than women. Moreover, men show markedly higher levels of media violence exposure and are more physically aggressive in real life. Accordingly, by emerging adulthood, compared with women, men have seen quite a bit more media violence and have had more experience with physical aggression in their own lives. It may be that media offensiveness may mediate the relationship between media violence and aggression for men, but only during childhood or adolescence. Because women consume less media violence (and possibly real-life violence), they may prove more offended when seeing it on screen; accordingly, we see these effects even in emerging adulthood. It should be noted, however, that the model being tested is with cross-sectional data. It is possible that a shortterm experimental study would find a different pattern.

Interestingly, religiosity as another person input predicts a number of outcomes in the study. First, religiosity is associated with diminished levels of physical aggression (for men only) and relational aggression (for both sexes). It is likely that many religious teachings discourage aggressive behavior in any form; accordingly, religious individuals may try more nonaggressive approaches to resolve problems. Second, religious individuals view less media violence than nonreligious individuals, and are accordingly more offended when exposed to media violence. In some religions, church members are encouraged to avoid media where there is gratuitous violence or strong sexual content. As a result of their religiosity and conscientious choice to consume less violence, they are more sensitized and therefore more offended when exposed. Although other research has established a connection between religiosity and 
level of offensiveness to other media content (Sapolsky et al., 2011), and between religiosity and media violence (Bushman, Ridge, Das, Key, \& Busath, 2007), to our knowledge this is the first study to examine these three variables concurrently.

As mentioned, the GAM also examines the "person in the situation." As such, this study considered the context in which consumption of media violence occurs. For instance, participants report feeling more offended when watching violence in the presence of children, followed by parents, and then members of the opposite sex, and to a lesser degree, peers. It may be that participants are uncomfortable viewing violent content deemed inappropriate for children, especially if worried about potential effects on child development (ASA, 2002) and their own responsibilities as caregivers and protectors. This provides evidence that the social context of the consumption episode may determine at least part of the viewer response and experience with the violent content. Future studies should test to see if the social context also moderates the effects of media violence on subsequent aggression, perhaps via changes in the judgments of offensiveness.

Situational considerations also extend to how the venues affect feelings of offense. Participants, regardless of gender, are most offended by violence portrayed in advertising, confirming our hypothesis that violence used to sell a product would be perceived as more offensive. Using violence in advertising may be more offensive if seen to glamorize violence or leveraged to make a profit. There is, however, an interesting paradox here. Most product advertising does not include violence of any sort (Brocato, Gentile, Laczniak, Maier, \& Ji-Song, 2010; Jones, Cunningham, \& Gallagher, 2010; Maguire, Sandage, \& Weatherby, 2000), though this can depend on genre (Gulas, McKeage, \& Weinberger, 2010). The ads that show the most violence are ads for violent TV shows or movies. It is unclear from our data how these types of ads would be judged. It is likely that our data represent people's beliefs about what they think they would find offensive, perhaps more than their memories of specific offensive content and their remembered feelings of offense. Experimental studies would be needed to test this, however.
Individuals, especially men, are more offended by violence in music than other genres, perhaps as music typically stimulates the auditory instead of the visual senses (except for in the form of music videos). However, other research shows that both the lyrics and the tone of the music have an influence on affect, hostility, and aggressive behavior (Brummert Lennings \& Warburton, 2011). Perhaps the combination of violent lyrics with a particularly "heavy" tone is more offensive to viewers than violence portrayed in other media. This contradicted our hypothesis that media without visual aspects or that allow the consumer to imagine the level of violence would be seen as less offensive.

In contrast, and in accordance with that hypothesis, violence in books was perceived as the least offensive. Although books may contain graphic portrayals of violence that can influence attitudes and behavior (Bushman et al., 2007; Coyne et al., 2011, 2012; Kirsh \& Olczak, 2002), such portrayals appear to be judged as less offensive. Although books stimulate the imagination and readers can construct images in their minds from violent passage, such text-based stimuli likely confronts less of the senses as compared with other media.

These findings suggest that viewers have a variety of reactions to and experiences with violence depending on the social and media contexts in which the violence is portrayed, even when the core content of the violence may be hypothetically the same. This suggests that research should directly compare media violence effects and the viewer experience in terms of media type.

We also examined the offensiveness of violence compared with other media content. Our results reveal that participants are most offended by sexual content, then profanity, and lastly violence. The pattern holds for both men and women, although media violence compared with other content is less offensive to men, confirming ASA (2002) research, which found violence is less offensive compared with sexual and profane content. Given the real-life consequences of violence and the emotional, social, and economic costs of societal violence (Hemenway, 2012; Kruse, Sørensen, Brønnum-Hansen, \& Helweg-Larsen, 2011), this finding was surprising. Generally, individuals are exposed to media violence far earlier than sexual content or profanity. For instance, Saturday morning cartoons contain ample violence and little to no explicit sexual content or profanity. Indeed, the average preschooler in the 
United States can easily access violent content from a number of programs (Pottler et al., 1995; Potter \& Smith, 2000; Wilson et al., 2002). Arguably, across childhood and adolescence, the heavy exposure to violent content is of such quantity and intensity that by emerging adulthood, graphic portrayals have lost much of their power to offend.

Finally, we examined some of the reasons why media violence was or was not considered offensive. Our analysis reveals a rich set of responses that center on a few main themes and support some of the quantitative findings. The primary reason cited is the perception that violence is inhumane, although this was still only given by a minority of participants. Many participants report feeling offended specifically because of media glamorization of an often cruel and brutal part of human society. Other participants express empathy toward victims, even fictional ones, vicariously experiencing the pain resulting from violence. When viewers feel empathy for victims of violence, they are less likely to be aggressive after viewing media violence (Funk, 2005; Krahé \& Möller, 2010). Other participants report that though media violence is not generally offensive, the nature of the portrayal influences their reactions. For example, participants note that extremely gratuitous portrayals or violence aimed at women or children is particularly offensive. A long research history supports this observationhow the violence is portrayed affects subsequent aggressive attitudes and behaviors (Anderson et al., 2003). A few participants said that concerns over the affect media violence may have on their own and others' behaviors often result in feeling offended. Thus, triggered feelings of offensiveness, whatever the source, may negate or temper the aggressive cognitions, emotions, and behaviors often resulting from exposure.

There are also varied reasons offered as to why media violence is not offensive. The most common deals with desensitization. Though researchers repeatedly show that desensitization can occur after continued exposure to media violence (Bartholow et al., 2006; Carnagey et al., 2007; Engelhardt et al., 2011; Funk, 2005; Krahé \& Möller, 2010; Thomas et al., 1977), it is interesting that some viewers recognize this process in themselves, and cite it as a reason for not having a reaction to media violence. Others felt that violence has a place in the media because aggression is a natural and expected part of human nature. This is in stark contrast to individuals who report feelings of offense based on the idea that violence was inhumane and should not be glamorized in the media. And finally, others report that when portrayals of violence or the settings in which it occurs are unrealistic (e.g., fantasy), they feel less offended.

The GAM (Anderson \& Bushman, 2002) provides a useful framework to understand how judgments of offensiveness relate to violence and aggression. As described earlier, person and situation inputs involved in a consumption episode have a tremendous influence on internal states, such as affect, arousal, and cognitions. In other words, responses to violent content do not always require an aggressive response, but rather reflect the influences derived from a host of input variables. These variables mediate responses to violent content, often through perceptions of offensiveness, which may mitigate the influence of the violence. Our results speak to the core nature of media violence and the viewer experience, and may spark future research on why viewers experience media violence in certain ways.

Though the study had a number of strengths including a large sample size and a mixed method, there were several limitations. Most notably, the data are cross-sectional, and thus, the direction of effects is unknown. We have modeled the data assuming that feelings of offense predict aggressive behavior; however, it is equally plausible that less aggressive people are more offended by portrays of violence in the media. Future longitudinal or experimental research should attempt to disentangle the direction of effects, though we suspect it is likely a bidirectional one. It is also possible that one or more third variables may be related to both offensiveness and aggression (e.g., empathy, physiological indicators, victimization). Furthermore, though we sampled participants in two different parts of the country and in two very different universities, the sample is not entirely representative of emerging adults as a whole, and thus invites some caution. Finally, the definition of "offensiveness" that we provided to participants involved feelings of disgust and/or embarrassment, two concepts widely discussed in the offensiveness literature (Shimp \& Stuart, 2004). However, this definition did not capture potentially related concepts, such as guilt or shame, which may occur as a result of viewing media violence. Though guilt and shame are closely related, they appear to have substantially different behavioral consequences (Shepherd, Spears, \& Manstead, 
2013; Tangney, Stuewig, \& Martinez, 2014). Accordingly, we hope that future research examines whether feelings of guilt and/or shame influence feelings of offensiveness and reactions to media violence as do feelings of disgust and embarrassment.

In sum, this study examines offensiveness and variables related to it, applying the GAM in order to more fully understand the mechanisms behind how and why media violence may or may not offend. These input variables combine to affect how individuals appraise and interpret content, and influence the internal state and ultimate responses of individuals to the content. The relationship between violence and aggression is a complex one, to be sure, yet exploring how personal and situational factors operate on judgments of offensiveness can expand our understanding of how consumers come to appraise, interpret, and ultimately respond to media violence.

\section{References}

Anderson, C. A., Berkowitz, L., Donnerstein, E., Huesmann, L., Johnson, J. D., Linz, D., . . . Wartella, E. (2003). The influence of media violence on youth. Psychological Science in the Public Interest, 4, 81-110.

Anderson, C. A., \& Bushman, B. J. (2002). Human aggression. Annual Review of Psychology, 53, 2751. http://dx.doi.org/10.1146/annurev.psych.53 .100901 .135231

Anderson, C. A., Gentile, D. A., \& Buckley, K. E. (2007). Violent video game effects on children and adolescents: Theory, research, and public policy. New York, NY: Oxford University Press. http://dx .doi.org/10.1093/acprof:oso/9780195309836.001 .0001

Archer, J. (2004). Sex differences in aggression in real-world settings: A meta-analytic review. Review of General Psychology, 8, 291-322. http://dx .doi.org/10.1037/1089-2680.8.4.291

ASA. (2002). Serious offense in non-broadcast advertising. Advertising Standards Authority. Retrieved January, 2013, from http://www.asa.org.uk

Bartholow, B. D., Bushman, B. J., \& Sestir, M. A. (2006). Chronic violent video game exposure and desensitization to violence: Behavioral and eventrelated brain potential data. Journal of Experimental Social Psychology, 42, 532-539. http://dx.doi .org/10.1016/j.jesp.2005.08.006

Brocato, D., Gentile, D. A., Laczniak, R. N., Maier, J. A., \& Ji-Song, M. L. (2010). Television commercial violence: Potential effects on children. Journal of Advertising, 39, 95-108. http://dx.doi .org/10.2753/JOA0091-3367390407
Brummert Lennings, H. I., \& Warburton, W. A. (2011). The effect of auditory versus visual violent media exposure on aggressive behaviour: The role of song lyrics, video clips and musical tone. Journal of Experimental Social Psychology, 47, 794799. http://dx.doi.org/10.1016/j.jesp.2011.02.006

Bushman, B. J., \& Anderson, C. A. (2001). Media violence and the American public: Scientific facts versus media misinformation. American Psychologist, 56, 477-489. http://dx.doi.org/10.1037/ 0003-066X.56.6-7.477

Bushman, B. J., Chandler, J., \& Huesmann, L. R. (2010). Do violent media numb our consciences? In W. Koops, D. Brugman, T. J. Ferguson, A. F. Sanders, W. Koops, D. Brugman, \& A. F. Sanders (Eds.), The development and structure of conscience (pp. 237-251). New York, NY: Psychology Press.

Bushman, B. J., Ridge, R. D., Das, E., Key, C. W., \& Busath, G. L. (2007). When god sanctions killing: Effect of scriptural violence on aggression. Psychological Science, 18, 204-207. http://dx.doi.org/ 10.1111/j.1467-9280.2007.01873.x

Carnagey, N. L., \& Anderson, C. A. (2003). Theory in the study of media violence: The general aggression model. In D. A. Gentile (Ed.), Media violence and children: A complete guide for parents and professionals (pp. 87-105). Westport, CT: Praeger Publishers/Greenwood Publishing Group.

Carnagey, N. L., Anderson, C. A., \& Bushman, B. J. (2007). The effect of video game violence on physiological desensitization to real-life violence. Journal of Experimental Social Psychology, 43, 489496. http://dx.doi.org/10.1016/j.jesp.2006.05.003

Christy, T. P., \& Haley, E. (2008). The influence of advertising context on perceptions of offense. Journal of Marketing Communications, 14, 271-291. http://dx.doi.org/10.1080/13527260802141272

Coyne, S. M., Callister, M., Pruett, T., Nelson, D. A., Stockdale, L., \& Wells, B. M. (2011). A Mean Read: Aggression in adolescent English Literature. Journal of Children and Media, 5, 411-425. http:// dx.doi.org/10.1080/17482798.2011.587148

Coyne, S. M., Nelson, D. A., \& Underwood, M. K. (2010). Aggression in childhood. In P. K. Smith \& C. H. Hart (Eds.), The Wiley-Blackwell handbook of childhood social development (2nd ed., pp. 491509). Chichester, West Sussex: Wiley-Blackwell.

Coyne, S. M., Ridge, R., Stevens, M., Callister, M., \& Stockdale, L. (2012). Backbiting and bloodshed in books: Short-term effects of reading physical and relational aggression in literature. British Journal of Social Psychology, 51, 188-196. http:// dx.doi.org/10.1111/j.2044-8309.2011.02053.x

Coyne, S. M., Stockdale, L. A., Nelson, D. A., \& Fraser, A. (2011). Profanity in media associated with attitudes and behavior regarding profanity use 
and aggression. Pediatrics, 128, 867-872. http://dx .doi.org/10.1542/peds.2011-1062

Engelhardt, C. R., Bartholow, B. D., Kerr, G. T., \& Bushman, B. J. (2011). This is your brain on violent video games: Neural desensitization to violence predicts increased aggression following violent video game exposure. Journal of Experimental Social Psychology, 47, 1033-1036. http://dx .doi.org/10.1016/j.jesp.2011.03.027

Fahy, J., Denise, S., William, P., \& Ferrell, O. C. (1995). Advertising sensitive products. International Journal of Advertising, 13.

Fanti, K. A., Vanman, E., Henrich, C. C., \& Avraamides, M. N. (2009). Desensitization to media violence over a short period of time. Aggressive Behavior, 35, 179-187. http://dx.doi.org/10.1002/ ab. 20295

Funk, J. B. (2005). Children's exposure to violent video games and desensitization to violence. Child and Adolescent Psychiatric Clinics of North America, 14, 387-404, vii-viii. http://dx.doi.org/10.1016/j.chc .2005 .02 .009

Funk, J. B., Baldacci, H. B., Pasold, T., \& Baumgardner, J. (2004). Violence exposure in real-life, video games, television, movies, and the internet: Is there desensitization? Journal of Adolescence, 27, 23-39. http://dx.doi.org/10.1016/j.adolescence .2003.10.005

Gentile, D. A. (2008). The rating systems for media products. In S. Calvert \& B. Wilson (Eds.), Handbook of children, media, and development (pp. 527-551). Oxford, England: Blackwell Publishing. http://dx.doi.org/10.1002/9781444302752.ch23

Gentile, D. A., Anderson, C. A., Yukawa, S., Ihori, N., Saleem, M., Shibuya, A., . . . Sakamoto, A. (2010). The effects of prosocial video games on prosocial behaviors: International evidence from correlational, longitudinal, and experimental studies. Personality and Social Psychology Bulletin, 35, 752-763. http://dx.doi.org/10.1177/ 0146167209333045

Gentile, D. A., Lynch, P. J., Linder, J. R., \& Walsh, D. A. (2004). The effects of violent video game habits on adolescent hostility, aggressive behaviors, and school performance. Journal of Adolescence, 27, 5-22. http://dx.doi.org/10.1016/j .adolescence.2003.10.002

Gentile, D. A., Maier, J. A., Hasson, M. R., \& Lopez de Bonetti, B. (2011). Parents' evaluation of media ratings a decade after the television ratings were introduced. Pediatrics, 128, 36-44. http://dx.doi .org/10.1542/peds.2010-3026

Gulas, C. S., McKeage, K. K., \& Weinberger, M. G. (2010). It's just a joke: Violence against males in humorous advertising. Journal of Advertising, 39, 109-120. http://dx.doi.org/10.2753/JOA00913367390408

Hemenway, D. (2012). Costs of firearm violence:
How you measure things matters. In D. M. Patel \& R. M. Taylor (Eds.), Social and economic costs of violence: Workshop summary (pp. 60-63). Washington, DC: National Academies Press.

Huesmann, L. R., Eron, L. D., Klein, R., Brice, P., \& Fischer, P. (1983). Mitigating the imitation of aggressive behaviors by changing children's attitudes about media violence. Journal of Personality and Social Psychology, 44, 899-910. http://dx.doi.org/ 10.1037/0022-3514.44.5.899

Jones, T., Cunningham, P. H., \& Gallagher, K. (2010). Violence in advertising: A multilayered content analysis. Journal of Advertising, 39, 11-36. http://dx.doi .org/10.2753/JOA0091-3367390402

Kaiser Family Foundation. (2010). Generation M2: Media in the lives of 8- to 18-year olds. Menlo Park, CA: Kaiser Family Foundation.

Kirsh, S. J., \& Olczak, P. V. (2002). Violent comic books and judgments of relational aggression. $\mathrm{Vi}$ olence and Victims, 17, 373-380. http://dx.doi.org/ 10.1891/vivi.17.3.373.33661

Krafka, C., Linz, D., Donnerstein, E., \& Penrod, S. (1997). Women's reactions to sexually aggressive mass media depictions. Violence Against Women, 3, 149-181. http://dx.doi.org/10.1177/ 1077801297003002004

Krahé, B., \& Möller, I. (2010). Longitudinal effects of media violence on aggression and empathy among German adolescents. Journal of Applied Developmental Psychology, 31, 401-409. http://dx .doi.org/10.1016/j.appdev.2010.07.003

Krahé, B., Möller, I., Huesmann, L. R., Kirwil, L., Felber, J., \& Berger, A. (2011). Desensitization to media violence: Links with habitual media violence exposure, aggressive cognitions, and aggressive behavior. Journal of Personality and Social Psychology, 100, 630-646. http://dx.doi.org/ 10.1037/a0021711

Kruse, M., Sørensen, J., Brønnum-Hansen, H., \& Helweg-Larsen, K. (2011). The health care costs of violence against women. Journal of Interpersonal Violence, 26, 3494-3508. http://dx.doi.org/10.1177/ 0886260511403754

Leavitt, C. E., Nelson, D. A., Coyne, S. M., \& Hart, C. H. (2013). Adolescent disclosure and concealment: Longitudinal and concurrent associations with aggression. Aggressive Behavior, 39, 335345. http://dx.doi.org/10.1002/ab.21488

Leone, R. (2002). Contemplating ratings: An examination of what the MPAA considers "too far for R" and why. Journal of Communication, 52, $938-$ 954. http://dx.doi.org/10.1111/j.1460-2466.2002 .tb02582.x

Lewis, C. A., Shevlin, M., McGuckin, C., \& Navrátil, M. (2001). The Santa Clara strength of religious faith questionnaire: Confirmatory factor analysis. Pastoral Psychology, 49, 379-384. http://dx.doi .org/10.1023/A:1010370728546 
Linz, D., \& Donnerstein, E. (1989). The effects of counter-information on the acceptance of rape myths. In D. Zillmann \& J. Bryant (Eds.), Pornography: Research advances and policy considerations (pp. 259-288). Hillsdale, NJ, England: Erlbaum, Inc.

Linz, D. G., Donnerstein, E., \& Penrod, S. (1988). Effects of long-term exposure to violent and sexually degrading depictions of women. Journal of Personality and Social Psychology, 55, 758-768. http://dx.doi.org/10.1037/0022-3514.55.5.758

Lofland, J., Snow, D., Anderson, L., \& Lofland, L. H. (2006). Analyzing social settings: A guide to qualitative observation and analysis. Toronto, Ontario, Canada: Wadsworth.

Maguire, B., Sandage, D., \& Weatherby, G. A. (2000). Violence, morality, and television commercials. Sociological Spectrum, 20, 121-143. http://dx.doi.org/10.1080/027321700280053

Nelson, D. A. (2005). Peer and Romantic Relations Inventory-Self Report (PRRI-S). Unpublished measure. Provo, UT: Brigham Young University.

Nelson, D. A., Coyne, S. M., Swanson, S. M., Hart, C. H., \& Olsen, J. A. (2014). Parenting, relational aggression, and borderline personality features: Associations over time in a Russian longitudinal sample. Development and Psychopathology, 26, 773787. http://dx.doi.org/10.1017/S0954579414000388

Olivera La Rosa, A., \& Roselló Mir, J. (2013). On the relationships between disgust and morality: A critical review. Psicothema, 25, 222-226.

Pottler, J. W., Vaughan, M. W., Warren, R., Howley, K., Land, A., \& Hagemeyer, J. C. (1995). How real is the portrayal of aggression in television entertainment programming? Journal of Broadcasting and Electronic Media, 39, 496-516. http://dx.doi .org/10.1080/08838159509364322

Potter, W. J., \& Smith, S. (2000). The context of graphic portrayals of television violence. Journal of Broadcasting and Electronic Media, 44, 301-323. http://dx.doi.org/10.1207/s15506878jobem4402_9

Riddle, K., Eyal, K., Mahood, C., \& Potter, W. (2006). Judging the degree of violence in media portrayals: A cross-genre comparison. Journal of Broadcasting and Electronic Media, 50, 270-286. http://dx.doi.org/10.1207/s15506878jobem5002_6

Sapolsky, B. S., Shafer, D. M., \& Kaye, B. K. (2010). Rating offensive words in three television program contexts. Mass Communication and Society, 14, 4570. http://dx.doi.org/10.1080/15205430903359693

Shepherd, L., Spears, R., \& Manstead, A. S. (2013). The self-regulatory role of anticipated group-based shame and guilt in inhibiting in-group favoritism. European Journal of Social Psychology, 43, 493504.

Shimp, T. A., \& Stuart, E. W. (2004). The role of disgust as an emotional mediator of advertising effects. Journal of Advertising, 33, 43-53. http:// dx.doi.org/10.1080/00913367.2004.10639150

Stockdale, L. A., Coyne, S. M., Nelson, D. A., \& Padilla-Walker, L. M. (2013). Read anything mean lately? Associations between reading aggression in books and aggressive behavior in adolescents. $\mathrm{Ag}$ gressive Behavior, 39, 493-502.

Strauss, A., \& Corbin, J. (1998). Basics of qualitative research. Thousand Oaks, CA: Sage.

Tangney, J. P., Stuewig, J., \& Martinez, A. G. (2014). Two faces of shame: The roles of shame and guilt in predicting recidivism. Psychological Science, 25, 799-805. http://dx.doi.org/10.1177/ 0956797613508790

Thomas, M. H., Horton, R. W., Lippincott, E. C., \& Drabman, R. S. (1977). Desensitization to portrayals of real-life aggression as a function of exposure to television violence. Journal of Personality and Social Psychology, 35, 450-458. http://dx.doi.org/ 10.1037/0022-3514.35.6.450

Timmer, J. (2009). Violence as obscenity: Offensiveness and the First Amendment. Communication Law and Policy, 15, 25-54. http://dx.doi.org/ 10.1080/10811680903446224

Vogt, W. P. (2000). Dictionary of statistics and methodologies: A non-technical guide for the social sciences (2nd ed.). Thousand Oaks, CA: Sage.

Waller, D. (1999). Attitudes towards offensive advertising: An Australian study. Journal of Consumer Marketing, 16, 288-295. http://dx.doi.org/ $10.1108 / 07363769910271513$

Ward, L. (2003). Understanding the role of entertainment media in the sexual socialization of American youth: A review of empirical research. Developmental Review, 23, 347-388. http://dx.doi.org/ 10.1016/S0273-2297(03)00013-3

Wilson, B. J. (1989). Desensitizing children's emotional reactions to the mass media. Communication Research, 16, 723-745. http://dx.doi.org/10.1177/ 009365089016006001

Wilson, B. J., Smith, S. L., Potter, W. J., Kunkel, D., Linz, D., Colvin, C. M., \& Donnerstein, D. (2002). Violence in children's television programming: Assessing the risks. Journal of Communication, 52, 5-35. http://dx.doi.org/10.1111/j.1460-2466 .2002.tb02531.x 


\section{Appendix}

\section{Media Offensiveness Questionnaire}

To the best of your ability, please answer the following questions pertaining to violence, sexual content, and profanity in the media. Each question will be based on a scale of 1-7 $(1=$ not offensive and 7 = highly offensive).

The word "offended" can be taken to mean "feelings of repulsion and/or feeling uncomfortable/ awkward."

\section{The following questions will pertain to violence in the media."}

Note: Violence involves physical force intended to hurt another person who does not wish to be harmed. Examples include shooting, stabbing, punching, kicking, etc.

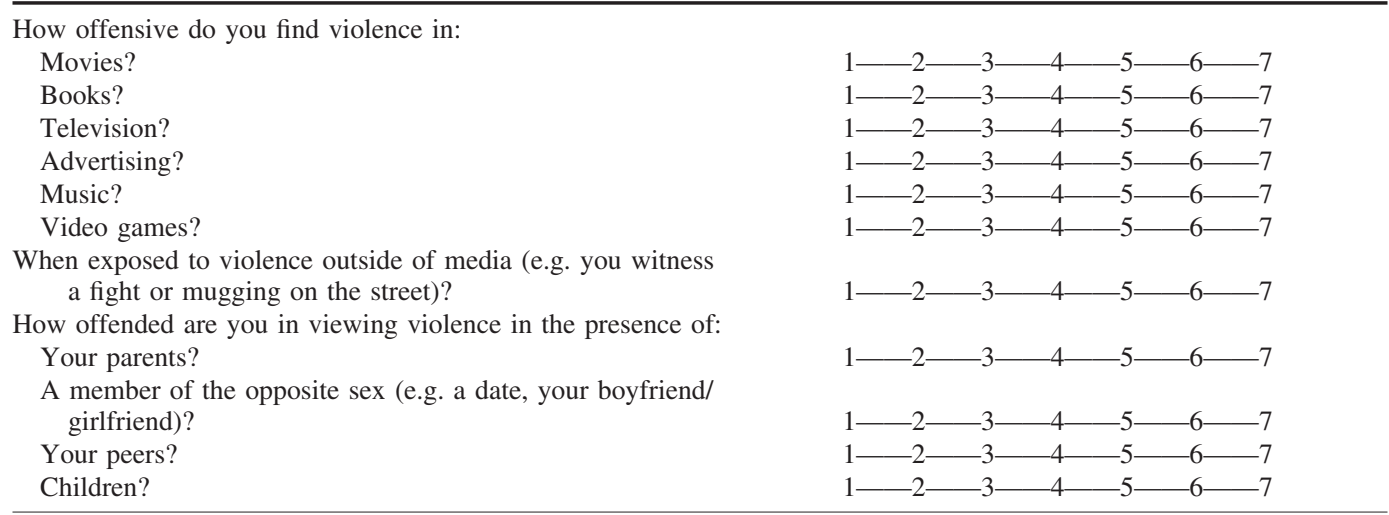

Note. Participants also completed similar scales related to sex and profanity. These are not included here, though can be obtained by contacting the first author. 